\title{
Acerca da sensitividade tátil na teoria freudiana
}

On Tactile Sensitivity

in Freudian Theory

\section{Carlota Ibertis Universidade Federal da Bahia [UFBA]}

\section{RESUMO}

Como é sabido, o empirismo freudiano dá especial relevância para as sensaçóes visuais e auditivas. Por outro lado, não fica claro, por falta de explicitação, se Freud valoriza as sensaçóes táteis da mesma forma que essas, embora elas estejam presentes em vários momentos-chave da vida psíquica. Com base nisso, o presente artigo explora o significado das sensaçóes táteis na teoria freudiana, examinando suas funçóes na figuração onírica, nas pulsóes parciais da infância e na instauração do eu. A análise mostra uma estreita conexão entre as sensaçóes táteis e o afeto, sugerindo que a consideração freudiana sobre estas sensaçóes requer reavaliação.

\section{PALAVRAS-CHAVE}

Sensaçôes táteis; Imagens mnêmicas; Representação; Afeto.

\begin{abstract}
As is well known Freudian empiricism gives special relevance to visual and auditory sensations. On the other hand, and although tactile sensations are present at several key moments of psychic life, it is unclear whether Freud valued the later to the same extent as the former since he did not explicitly state his views on this issue. The present article explores the meaning of tactile sensations in Freudian theory, examining their functions in dream figuration, partial impulses of childhood, and the instauration of the self. The analysis shows a close connection between tactile sensations and affect, suggesting that Freud's views on tactile sensations need to be reevaluated.
\end{abstract}

\section{KEY WORDS}

Tactile Sensations; Mnemonic Images; Representation; Affect. 
Em vários textos Freud salienta a relevância das diferentes sensaçôes para a sua teoria. ${ }^{\mathrm{I}}$ Com especial atenção ora destaca as visuais, ora as auditivas, destacando seu papel no funcionamento psíquico da linguagem e do conhecimento de objetos. Embora Freud não se detenha nesse ponto, pode-se afirmar que, para ele, as sensaçóes táteis caracterizam-se por serem protagonistas, por exemplo, das vivências mais primitivas, como as de satisfação e do surgimento das pulsôes parciais. Dessa maneira, poder-se-ia dizer que a teoria freudiana não se limita a afirmar uma tese empírico-sensualista em termos gerais (Freud, 20I4, pp. 243-244), mas considera a especificidade do papel de cada tipo de sensações para a vida psíquica. ${ }^{2}$

Na correspondência com Fliess encontram-se prenúncios de como Freud entenderá o papel de sensaçóes auditivas na formação das fantasias e o das sensaçôes visuais para os sonhos (Freud, I976a, pp. 288-289). Mas é no texto dedicado às afasias que explicita os pressupostos teóricos dessa consideração, por meio do conceito de representação enquanto complexo associativo que reúne os complexos representação-palavra e representação-objeto. Ambos são concebidos como associaçóes de imagens de vários tipos: o primeiro associa imagens visuais, auditivas e de movimento da fala e da escrita; o segundo associa imagens sensíveis de toda espécie. No esquema freudiano, a representação-objeto, complexo aberto, une-se, através da sua imagem visual, com a imagem de som da representação-palavra, complexo fechado (Freud, 2013, p. IO2). ${ }^{3}$

Sugere-se assim a preponderância da sensação visual-auditiva sobre as demais, no que concerne à função de representar: enquanto a imagem de som representa a palavra, a visual representa o objeto. Desse modo, na perspectiva freudiana, a união do complexo de palavra com o de objeto constitui as dimensôes de significante por uma parte, e de significado e referência da linguagem por outra (Freud, 2013, p. IO4). Nesse sentido, Hervé Huot (I99I, p. 89) observa que, para Freud, o vínculo da linguagem com o mundo dos "objetos" sensíveis passa pelo olho, ou seja, pela imagem visual do objeto e pela fala, ou imagem sonora da palavra. No texto das afasias, Freud afirma enfaticamente: "as imagens visuais são as partes mais salientes e mais importantes de nossas represen-

I Abordar o tema das sensaçóes na teoria freudiana, implica em considerar tanto o ato de sentir e o seu resultado, a sensação ou impressão, quanto as imagens como resultado dos traços mnêmicos investidos daquelas. No presente texto limitar-nos-emos a mencionar a especificidade das sensaçóes visuais e auditivas com o intuito de evidenciar as diferenças com as sensaçóes táteis, deixando para outro momento a abordagem das olfativas e gustativas bem como o aprofundamento da análise das visuais e auditivas.

2 No que concerne à análise da contribuição de cada sentido para a vida mental, e em particular do tato, um antecedente interessante, pela proximidade em mais de um aspecto com a perspectiva freudiana, o fornecem Condillac e Diderot no século xvıII. De forma direta, as investigaçóes sobre fisiologia dos sentidos da Escola de Helmholtz influenciaram os anos de formação de Freud, em especial o período de pesquisa no Instituto de Fisiologia de Viena dirigido por Brücke (Amacher, 1965$)$.

3 Edmond Cros afirma que a articulação freudiana entre visão e linguagem estaria vinculada à tese de Helmholtz que discrimina entre impressão, gravada passivamente pela retina, e sensação, produto da atividade cerebral. O autor salienta também o interesse do cientista na audiçáo (Cros, 20II, p. 80). 
taçôes de objeto" (Freud, 20I3, p. IO5). ${ }^{4}$

Em relação às sensações auditivas, a dimensão sonora da linguagem cobra importância fundamental, por uma parte, não apenas quando considerada a figuração onírica, mas também a técnica analítica e os chistes. É notável a sensibilidade de Freud no que diz respeito à "dimensão sonora da linguagem" nos termos utilizados por Bourlot e Vives. No artigo cujo título alude à importância do sonoro na teoria freudiana, eles salientam a qualidade decomponível das palavras a serviço da interpretação dos sonhos. Exemplo paradigmático disso é a análise do sonho do próprio Freud em que aparece a formação do neologismo Autodidasker. ${ }^{6}$ Com efeito, nessa análise, ele privilegia o sonoro, pois a decomposição segue menos a linha do sentido que a da sonoridade. $\mathrm{O}$ brincar com nomes e sílabas de que fala Freud figura camadas de desejos que o sonho "realiza" de forma alucinatória. Assim, os sons tornam-se materiais elementares da figuração dos sonhos pela equivocidade das palavras e sua proximidade sonora (Bourlot e Vives, 20I2, p. 506).

Por outro lado, como salienta Lecourt, as vozes dos pais têm um papel determinante na constituição do ideal do Eu e dos mandamentos superegóicos derivados do complexo edipiano (I997, pp. 5I-52). Lemos em Freud: "A incitação a formar o ideal do Eu, cuja tutela foi confiada à consciência moral, partiu da influência crítica dos pais intermediada pela voz, aos quais se juntaram no curso do tempo os educadores, instrutores e, como uma hoste inumerável e indefinível." (Freud, 20I0, p. 42, grifos nossos). Assim, além da preeminência cognitiva que têm quando aliadas às sensaçôes visuais, as sensaçôes auditivas ganham um papel decisivo na formação da instância superegóica.

No que diz respeito às sensaçóes táteis, Freud descreve seu papel ao abordar três temas capitais: as noçóes das vivências de satisfação e de dor, as experiências autoeróticas da primeira infância e a formação do Eu. Se comparado o tratamento dispensado às outras sensaçôes, é possível constatar que, enquanto o papel das visuais é entendido como eminentemente representacional e cognitivo, e o das auditivas diz respeito nomeadamente à linguagem, às fantasias e à formação superegóica, o papel das sensaçôes táteis apresenta-se menos particularizado, porém fundamental para a teoria.? Com efeito,

4 Entretanto, no mesmo texto sobre as afasias, Freud salienta que diante da falta de imagens visuais, outras imagens sensíveis podem substituí-las para poder usar a linguagem (Freud, 2013, p. IO4). Por exemplo, no caso da paciente de Farges mencionado por Freud, a perda da visão acarreta a impossibilidade de comunicaçáo e de fala: a paciente não reagia a chamados, repetindo sem cessar "não quero, não posso". Não reconhecia a voz do médico, mas bastava que ele a segurasse pelo pulso para que ela o reconhecesse e começasse a falar normalmente sem distúrbios de linguagem enquanto durasse o contato (ibid.).

5 Freud et la dimension sonore du langage, 2012.

6 Como se recordará, o sonhante lembra vividamente da expressão Autodidasker que condensa as palavras Autor, Autodidakt e Lasker, segundo as associações as que Freud chega na interpretação (1976b, pp. 305-307).

7 Edmond Cross salienta o interesse especial de Freud pelo processo de percepção visual na época do Instituto de Fisiologia de Viena bem como em Paris ao se entrevistar com o oftalmologista Parinaud e o fisiologista ocular Cornu. De modo semelhante, Freud pesquisará sobre o centro acústico no córtex para relacionar ambos temas no estudo sobre as afasias (Cros, 20II, p. 76). 
sobre as sensaçôes táteis, Freud não elabora uma reflexão teórica explícita, em que faça alusão à contribuição específica destas equiparável à destinada às visuais e auditivas no texto das afasias. No que segue, sem pretensão de exaurir a questão, examinamos afirmaçóes freudianas acerca das sensaçôes táteis nos sonhos, no erotismo infantil e na formação do Eu em busca de uma chave para melhor compreender o teor do papel a elas atribuído na teoria.

\section{Sensações táteis nos sonhos}

Como observamos em outro lugar, a figurabilidade é concebida por Freud como o conjunto das condiçôes de possibilidade da figuração onírica que abrangem tanto a capacidade de um pensamento ser expresso em imagens quanto o funcionamento do aparelho psíquico que permite a operação de figurar (Ibertis, 20I7, p. 6). E esta, por sua vez, é concebida como o caminho regressivo em direção às imagens mnêmicas originadas em impressóes sensíveis, o que pressupóe a perspectiva metapsicológica do aparelho psíquico presente no capítulo sétimo da Interpretação dos sonhos e na Carta 52.

O escrito Sobre a concepção das afasias explica, do ponto de vista freudiano, o fato dos sonhos se manifestarem predominantemente em imagens visuais: sendo essas as que melhor representam os objetos, a maneira mais direta de transpor os pensamentos oníricos em imagens resulta de fazê-lo com base nos traços mnêmicos de sensaçóes visuais. Contudo, elas não são a única via de figuração como atestam alguns (poucos) exemplos freudianos. ${ }^{8}$

$\mathrm{Na}$ Interpretação dos sonhos, encontram-se, dentre os sonhos típicos, casos particularmente interessantes para o tema das sensaçôes táteis. Trata-se do grupo que reúne os sonhos em que voamos, flutuamos no ar, caímos, nadamos, etc. De acordo com Freud, tais sonhos repetem impressóes de infância vinculadas a jogos de movimento caros às crianças; em especial, aqueles que acarretam um pouco de susto ou de vertigem. Freud salienta que amiúde os sonhos que resgatam tais impressôes despertam sensaçóes sexuais prazerosas que se traspóem em angústia (1996, p. 428). Em relação a esses sonhos, Freud rejeita a explicação de que as sensaçôes epidérmicas ou do movimento pulmonar presentes no momento do sono seriam a causa dos sonhos de voar ou cair, sendo necessário distinguir entre fonte e conteúdo dos sonhos:

Assim, tenho boas razóes para rejeitar a teoria de que o que provoca os sonhos com voos e quedas é o estado de nossas sensaçóes táteis durante o sono, ou as sensaçóes de movimento de nossos pulmóes, e assim por diante. A meu ver, essas próprias sensaçóes são reproduzidas como parte da lembrança à qual remonta o sonho: isto é, são parte do conteúdo do sonho, e não sua fonte (Freud, 1996, p. 428, grifos do autor).

8 Relatos de sonhos de não videntes podem ser encontrados no artigo de Kastrup "Será que cegos sonham? O caso das imagens táteis distais", 2013. 
Segundo isso, as sensaçóes de voar e cair pertencem ao conteúdo onírico e derivam de imagens mnêmicas da infância lembradas por quem sonha. Todavia, enquanto os sonhos de voar ou flutuar são prazerosos e requerem interpretação individual, aos de queda correspondem mais frequentemente sentimentos de angústia e figuram o que se concebia como falta moral na época: ter cedido à tentação erótica (Freud, 1996, p. 429).

Freud também se refere a sonhos relativos à água. Ao abordá-los, ele reproduz o seguinte sonho: "Em sua estação de veraneio, no Lago de..., ela mergulhou nas águas escuras, exatamente no ponto em que a pálida lua se espelhava" (ibid., p. 434, grifos do autor). Um belo sonho, figurado com uma combinação de sensaçóes táteis e visuais cuja interpretação é alcançada invertendo "mergulhar na água" por "sair da água", e considerando o emprego da gíria em que "lune” é usada por traseiro de modo que o sonho manifesto figura o ato de nascer segundo a versão infantil (ibid., p. 435). $\mathrm{Na}$ mesma página, em uma nota acrescentada em 1909, Freud observa que "o ato de nascer é a primeira experiência de angústia, e, portanto, a fonte e protótipo do afeto de angústia" (ibid., n. 2, grifos do autor). ${ }^{9}$

No artigo já mencionado, salientamos que a figurabilidade dos pensamentos oníricos em imagens é determinada pela possibilidade de desandar o processo de formação de pensamentos a partir de sensaçóes primitivas. Assim, em primeiro lugar, os pensamentos devem ser suscetíveis de serem expressos em imagens; em segundo lugar, o sistema mnemônico de um indivíduo deve dispor de imagens adequadas à expressão dos pensamentos oníricos em questão; e, em terceiro lugar, tal sistema deve contar com redes associativas que permitam a vinculação dessas imagens adequadas com os pensamentos a serem transformados (Ibertis, 20I7, p. I6).

As impressóes táteis prestam-se, assim, a traduzir afetos, pois fizeram parte de experiências primitivas, que são, reconhecidamente, para Freud, muito intensas. Como resultado da elaboração do sonho por via regrediente, as imagens oníricas táteis e cinestésicas figuram pensamentos latentes em que predominam afetos básicos como prazer e angústia. Enquanto objetos, açôes e situaçôes, na sua dimensão mais objetiva, são suscetíveis de serem figurados mais adequadamente de forma visual ou auditiva, a dimensão afetiva desses seria figurável através de imagens táteis e cinestésicas ${ }^{\mathrm{I}}$. De modo que, quando os afetos constituem o aspecto mais saliente do sonho, as imagens táteis e cinestésicas teriam maior aptidão para figurá-los em função das características intrínsecas das sensaçôes que lhes dão origem. Em nossa opinião, deve-se compreender esse ponto à luz das vivências mais primitivas.

9 Cabe lembrar que o afeto contempla várias conotaçóes: a primeira diz respeito à liberação de quantidade; a segunda refere-se à reprodução de vivências que acarreta essa liberação de quantidade; a terceira remete às sensaçóes que esse processo desperta. De início, no Projeto, o termo apenas designa a reprodução de uma vivência dolorosa para posteriormente indicar qualquer reprodução que implique irrupção de quantidade, incluindo a da vivência de satisfação (Ibertis, 2008, p. 46).

Io $\mathrm{O}$ caso de pessoas cegas impóe um estudo específico de como acontece a função representacional uma vez que audiçáo, olfato, sabor e tato substituem o papel da visão. 


\section{Sensações táteis e pulsões sexuais infantis}

Como se sabe, para Freud o modelo da sexualidade infantil encontra-se no ato de sugar sem finalidade de alimentação e com satisfação no próprio corpo, ou seja, de forma definida como autoerótica. A esse respeito, ele afirma que "o ato da criança que chupa é determinado pela busca de um prazer — já vivido e agora lembrado" — ligado à "primeira e mais vital atividade" da criança que consiste em mamar no peito materno (Freud, 20I6, p. 85). Com isso, a definição das pulsôes parciais encontra a sua origem no apoio de funçôes vitais.

No caso da pulsão oral, o afluxo de leite quente que satisfaz a necessidade de alimento teria causado a sensação de prazer, doravante associada aos lábios e à boca. A esse respeito, as impressóes sensíveis, sobretudo táteis, olfativas e de paladar, que estão na origem da vivência de satisfação, trazem consequências decisivas na constituição psíquica do lactente e, posteriormente, na sexualidade adulta ao moldarem pulsóes e desejos. Ora, dentre os tipos de sensaçóes, as táteis são as que se ligam diretamente com o conceito de zona erógena, definida como a "parte da pele ou mucosa em que estímulos de determinada espécie provocam uma sensaçáo de prazer de certa qualidade" que definem as pulsóes parciais (ibid., p. 87).

De modo geral, quaisquer partes da pele ou das mucosas são suscetíveis de erogeneidade, dependendo mais da qualidade do estímulo que da natureza da parte corporal de que se trate (ibid., p. 88). Em outras palavras, é a qualidade da sensação tátil, do modo de ser tocado e de tocar, que vai determinar o efeito prazeroso e seu correspondente registro mnêmico associado à satisfação. De forma análoga à oral, as demais partes do corpo tornam-se suscetíveis de produzir prazer a partir de experiências sensíveis prazerosas que em diante demandam ser repetidas.

Acerca da significação das impressôes táteis, Didier Anzieu observa que o conjunto da superfície do corpo do bebê e da mãe é objeto de experiências tão importantes para a qualidade emocional, a estimulação da confiança, do prazer e do pensamento quanto as experiências ligadas à sucção e à excreção (Anzieu, 1995, p. 60). Por ocasiáo do banho, do colo e demais gestos, os cuidados maternos provocam estimulação involuntária da pele que logo se transformam em meios de comunicação mãe-bebê, que de início é essencialmente afetivo-emocional.

Se consideradas em geral, as sensaçóes epidérmicas e de movimento resultam não apenas inúmeras como também, algumas delas, difusas, para além de omnipresentes. Devido à precocidade, quantidade, variedade e rapidez com que essas experiências se sucedem, é possível que nem todas cheguem a ser registradas nos complexos associativos próprios das representaçóes de objeto. Desse modo, algumas de tais impressóes originariam traços sem referência a um objeto determinado, mas de qualquer maneira com valor afetivo. ${ }^{\text {II }}$

II César e Sára Botella referem-se a traços sem a possibilidade de se tornarem lembranças insistindo em que "a ausência de conteúdo representável não quer dizer ausência de acontecimento" (2003, p. 239). 
O que está em questão aqui é a sensação que se chama “objeto" nas experiências mais primitivas prévias à dualidade eu e não-eu. Tratar-se-ia de conceber o registro deste último sem imagens sensíveis associadas do lado da representação correspondente? Ou do registro de imagens que não alcançam a constituírem complexos associativos mais acabados — ainda que tais complexos nunca sejam fechados — da representação de algo que, em todo caso, não corresponde a um objeto na realidade, mas à fusão indiscriminada, por exemplo, do seio materno e a boca do bebê ou do colo daquela e a pele deste, etc.? ${ }^{12}$

Em termos do par de conceitos freudianos de representaçáo e de afeto, a resposta é dada pela segunda alternativa enquanto objeto interno que satisfaz as pulsóes parciais (Coelho Jr., 200I, p. 42). Essa sorte de "proto-objeto", não encontrando confirmação ulterior na realidade, permanece "esquecido" ou "perdido". Todavia, embora a compreensão do que devamos entender por objeto das representaçóes mais primitivas possa ser questionado, é indubitável que às impressóes táteis da primeira infância correspondem intensas cargas de afeto o que explicaria, dentre outras coisas, a sua capacidade figurativa onírica. ${ }^{\mathrm{I3}}$

\section{Sensações táteis e o $\mathrm{Eu}^{\mathrm{14}}$}

A descrição de Anzieu acerca da relevância das sensaçóes epidérmicas desemboca na formulação do conceito do Eu-pele, mas antes remete à tese freudiana sobre o nascimento do Eu, condição de possibilidade da constituição de objetos externos. Em torno disso, encontra-se a formulação mais explícita da maneira como as sensaçôes táteis se inscrevem ou traduzem na psique em $O$ Eu e o Id:

O corpo, principalmente sua superfície, é um lugar do qual podem partir percepçôes internas e externas simultaneamente. É visto como um outro objeto, mas ao ser tocado produz dois tipos de sensaçóes, um dos quais pode equivaler a uma percepção interna. Já se discutiu bastante, na psicofisiologia, de que maneira o corpo sobressai no mundo da percepção (Freud, 20II, pp. 3I-32).

Freud alude aqui à especificidade das sensaçôes táteis do corpo que se desdobram em internas e externas. Tal como no Tratado das sensaçóes, de Condillac ${ }^{15}$, entrevemos a descoberta da diferença entre tocar o próprio corpo e outro alheio. Em um parágrafo

I2 Cf., por exemplo, a noção de pictograma em Piera Aulagnier. Diversos psicanalistas contemporâneos têm se ocupado das impressóes vivenciadas precocemente problematizando o limite entre o representável e o irrepresentável. Dentre outros, Ferenczi, Winnicott, André Green, Pierre Fédida, Didier Anzieu.

I3 No que concerne à relação das impressôes táteis e os sonhos apresentada na seção anterior, caberia indagar pelo destino dessas sensações cujo registro não se estabelece nos moldes de uma representação de objeto acabado ou que corresponda à realidade externa. Mesmo assim, elas poderiam servir à figuração onírica?

I4 Uma primeira versão desta seção foi desenvolvida em Tacto y reflexividad: una aproximación entre Condillac y Freud (Ibertis, 20I4).

I5 No Tratado das sensaçôes, com o auxílio da hipótese da estátua que ganha vida progressivamente, Condillac defende a tese do surgimento das ideias de eu e não-eu a partir da experiência da mão tocar o corpo próprio e corpos externos (Condillac, 1993, p. I26). 
semelhante, Anzieu destaca a estrutura reflexiva que inicialmente só possuem as sensaçôes táteis e da qual derivam todas as outras modalidades reflexivas: "a criança que toca com o dedo as partes de seu corpo experimenta as duas sensaçóes complementares de ser um pedaço de pele que toca, ao mesmo tempo de ser um pedaço de pele que é tocado" (Anzieu, I995, p. 84). Ouçamos Freud:

Também a dor parece ter nisso um papel, e o modo como adquirimos um novo conhecimento de nossos órgãos, nas doenças dolorosas, é talvez um modelo para a forma como chegamos à ideia de nosso corpo. $\mathrm{O}$ Eu é sobretudo corporal, não é apenas uma entidade superficial, mas ele mesmo a projeção de uma superfície (Freud, 20II, p. 3I-32).

A reflexividade acarreta a possibilidade de discernir entre si e o exterior e surge de experiências táteis e proprioceptivas sentidas como prazerosas ou desprazerosas e dolorosas, fato que outorga ao surgimento do Eu uma nuança afetiva. Assim, a sua instauração pode ser entendida como resultado da maneira como somos afetados desde o exterior e o interior. A seguir, Freud inclui uma nota da tradução inglesa de 1927 em que lemos:

Ou seja, o Eu deriva, em última instância, das sensações corporais, principalmente daquelas oriundas da superfície do corpo. Pode ser visto, assim, como uma projeçáo mental da superfície do corpo, além de representar, como vimos acima, as superfícies do aparelho psíquico (ibid., p. 32, n. 7).

Freud caracteriza o Eu como "a parte do Id modificada pela influência direta do mundo externo", com a mediaçáo do sistema percepção-consciência (ibid., p. 3I). Winograd e Costa Mendes observam que, para Freud, dizer que o Eu é corporal significa que sua origem o é, o que não é o mesmo que afirmar que seja "exclusivamente corporal" (2009, p. 2I8). Ao contrário, o Eu é simultaneamente superfície do corpo e projeção mental dessa superfície e, portanto, é possível afirmar que ele é ao mesmo tempo corporal e consciência do corporal (Winograd e Costa Mendes, 2009, p. 218).

Trata-se aqui, portanto, de um processo em que experiências perceptivas corporais são traduzidas psiquicamente de modo semelhante a como as pulsóes parciais se determinam pelo encontro entre impulsos originados no organismo e as sensaçóes provocadas pelo cuidado materno que adquire estatuto psíquico. Paralelamente, podemos dizer que o Eu se diferencia do Id, tornando-se instância psíquica pela incidência das experiências sensíveis, e entre essas, em primeiro lugar, as táteis.

Como mencionamos, Anzieu chama a atenção sobre a significação psíquica da pele enquanto superfície do corpo e fronteira que determina o interior e o exterior. A linguagem comum assim o evidencia: a pele é a referência básica segundo a qual são referidos os restantes dados sensoriais, pois se fala em "estabelecer ou manter contato" de diferentes tipos sem efetivamente se tocar. As expressôes "contato auditivo, visual, etc.", são adotadas por analogia com a experiência original de tocar. Em palavras do autor: "É sobre o modelo da reflexividade tátil que se constroem as outras reflexividades sensoriais (escutar-se emitir sons, sentir seu próprio odor, se olhar no espelho) e em seguida a reflexividade do pensamento" (Anzieu, 1995, pp. 83-84). 
Sobre as proibiçóes relativas às diversas formas de contato, Freud observa em Totem e tabu:

Como no tabu, a interdição principal e núcleo da neurose é a de contato, daí o nome "medo de toque", délire de toucher. A proibição se estende não só ao contato direto com o corpo, abrangendo o que designamos, em linguagem figurada, com a expressão "entrar em contato". Tudo que dirige os pensamentos para a coisa proibida, que produz um contato em pensamento com ela, é proibido tanto quanto o contato físico direto (Freud, 20I2, pp. 54-55).

Do poder que confere a ação de tocar algo ou alguém, nasce o tabu correspondente. Assim como a experiência tátil do toque é o modelo para qualquer outra forma metafórica de contato também a proibição de tocar é o modelo das interdiçôes dos outros tipos de contatos presentes no tabu e na neurose. Sob essa perspectiva, o tato cumpre a função de modelo, não somente das experiências dos demais sentidos como também da consciência de si e de todos os tipos de contato que definem as proibiçóes. Em nossa opinião, o amplo leque de aspectos psiquicamente relevantes em que o tátil é determinante não é evidenciado de modo suficiente por Freud, malgrado, como vimos, a importância que tem na articulação de sua teoria.

\section{Considerações finais. Sensações táteis no empirismo freudiano}

Como foi dito anteriormente, subjaz à teoria freudiana uma concepção empirista que identifica as sensaçôes como ponto de partida não apenas dos conteúdos da vida psíquica, mas também da sua constituição e o faz distinguindo a natureza particular de cada tipo dessas. Assim, enunciado de modo geral, as imagens mnêmicas de impressôes sensoriais são o primeiro material da psique, além da gênese do psiquismo ser deslanchada por estas (Freud, 20I4, pp. 243-244). A análise mostrou que no empirismo freudiano, a sensorialidade tátil sobressai juntamente com a auditiva e a visual.

No que concerne à elaboração onírica, o trabalho de figuração procede por via regrediente dos pensamentos latentes às impressóes mnêmicas, registros de sensaçóes passadas segundo uma lógica que privilegia as imagens visuais e auditivas para representar coisas, açóes e situaçóes. Nesse contexto, no entanto, as imagens originadas em sensaçóes táteis resultam a via de expressão de afetos fundamentais como prazer e angústia.

Em relação à vida psíquica infantil, as sensações táteis ligadas às zonas erógenas constituem a base para a definição das pulsôes sexuais da primeira infância bem como impressôes epidérmicas em geral inscrevem traços com significativo valor afetivo para a vida adulta. Esta afirmação resulta manifesta embora fique certa ambiguidade entre a noção de objeto nas experiências autoeróticas, por uma parte; e nas posteriores à distinção entre eu e a realidade exterior, por outra. ${ }^{16} \mathrm{~A}$ esse respeito, a pergunta sobre quais seriam as condiçóes de lembrança e os impactos das impressôes mais precoces continua aberta. ${ }^{17}$

I6 O artigo de Nelson Coelho Jr, "A noção de objeto na psicanálise freudiana” apresenta um panorama geral dos diversos significados de objeto.

I7 Exemplo do estado da questáo é o número da Revue française de psychanalyse, 2016/4, v. 80, dedicado integralmente ao tema das sensaçôes. 
Quanto ao surgimento do eu, a incidência das sensaçóes táteis nesse processo transfere o tom afetivo, que as caracteriza, à relação de si com o mundo externo. De modo que, pelas razóes apresentadas, dentre todas as sensaçôes e suas correspondentes imagens mnêmicas, as táteis parecem ter um papel proeminente no que diz respeito à dimensão afetiva da vida psíquica. ${ }^{18}$ Porém, em torno da sua importância nos parece haver certa tensão no discurso freudiano que oscila entre reconhecê-la e ofuscá-la.

Justamente, resulta curioso que Freud destaque de forma especial a importância da visão e da audição para a representação, mas não a do tato para o afeto, nem para a consciência de si. Embora as impressôes táteis se encontrem muito presente na base da sua teorização e a noção de afeto ser tão fundamental quanto a de representação, o papel do tato não é salientado da mesma forma no texto freudiano. Por um lado, o destaque outorgado às primeiras poder-se-ia compreender pelo interesse de Freud, nos anos de formação, nas concepçôes de Helmholtz sobre a fisiologia visual e auditiva juntamente com as pesquisas cujos resultados desembocam na noção de representação introduzida no estudo sobre as afasias, momento em que ainda ele não tinha elaborado, de forma mais acabada, a fórmula representação-afeto para dar conta das vivências psíquicas. ${ }^{19}$

Por outro, a ausência de destaque para as sensações do tato poder-se-ia entender pela mudança de perspectiva advinda do amadurecimento teórico em que o foco do interesse freudiano se desloca progressivamente de uma abordagem clássica da vida psíquica para a noção de pulsão em que se subentende a importância do afeto e, de forma correlata, das sensaçóes táteis. Contudo, a nosso ver, resta ainda conferir de forma detida se não haveria em Freud algum resquício de preconceito intelectualista que outorgaria maior realce à representação sobre o afeto e às sensaçóes visuais e auditivas em desmedro das táteis.

\section{Referências bibliográficas}

Amacher, P. (1965). "Freud's neurological educations and its influence on psychoanalytic theory". In: Psychological Issues, v. 4, n. 4.

Anzieu, D. (1995). Le Moi-peau, Paris: Dunod.

Aulagnier, P. (2003). La violence de l'interprétation: du pictogramme à l'énoncé, Paris: PUf.

Botella, C. e S. (2003). La figurabilidad psíquica, trad. Irene Agoff, Buenos Aires: Amorrortu.

Bourlot, G. e Vives, J.-M. (2012). "Freud et la dimension sonore du langage”. In: L'évolution psychiatrique, v. 77, pp. 503-517.

Coelho Jr., N. E. (20oI). "A noção de objeto na psicanálise freudiana”. In: Ágora: Estudos em Teoria Psicanalitica, Rio de Janeiro, v. 4, n. 2, jul./dec., pp. 37-49.

I8 Não insistiremos no presente texto no fato de que a significação da sensorialidade tátil também concerne ao cognitivo na medida em que, em primeiro lugar, determina a distinção entre eu e nãoeu; e, em segundo, estabelece a primeira forma de reflexividade.

I9 Ainda que presente em textos anteriores, a dimensão do afeto é introduzida de modo sistemático a par da representação no Projeto de psicologia de 1895 , de modo que as vivências são concebidas doravante sempre em termos de representação-afeto, adquirindo essa dimensão quantitativa além de ideativa (Ibertis, 2008, p. 46). 
Condillac, E. B. (1993). Tratado das sensaçôes, trad. Denis Bottman, Campinas: Ed. unicamp.

Cros, E. (2OII). "El campo cultural de la segunda mitad del siglo XIX y su articulación com la historia (Freud, Saussure, poética, pintura abstracta)". In: Sociocriticism, v. XxVI, n. I-2.

Diderot, D. (1979). Carta sobre os cegos para uso dos que veem, tradução Marilena Chaui e J. Guinsburg, São Paulo: Editora Abril Cultural.

Freud, S. (1976a). "Fragmentos de la correspondencia con Fliess". In: Freud, Obras Completas, traducción José L. Etcheverry, notas y comentarios James Strachey, Buenos Aires: Amorrort.

(1976b). "Interpretación de los sueños". In: Freud, Obras Completas, traducción José L. Etcheverry, notas y comentarios James Strachey, Buenos Aires: Amorrortu.

(I996). "Interpretação dos sonhos". In: Freud, Obras psicológicas completas: edição standard brasileira, tradução Jayme Salomão, notas e comentários James Strachey, Rio de Janeiro: Imago.

(2003). "Projeto de uma psicologia", tradução Osmyr Faria Gabbi Jr. In: GabBi Jr., Osmyr Faria, Notas a Projeto de uma psicologia: as origens utilitaristas da psicanálise, Rio de Janeiro: Imago.

(20II) "O Eu e o Id". In: Freud, Obras Completas, tradução Paulo César de Souza, São Paulo: Companhia das Letras, v. I6.

(20I2). "Totem e tabu". In: Freud, Obras Completas, tradução Paulo César de Souza, São Paulo: Companhia das Letras, v. II.

(2013) "Sobre a concepção das afasias. Um estudo crítico", tradução Emiliano de Brito Rossi. In: Freud, Obras Incompletas de Sigmund Freud. Belo Horizonte: Autêntica Editora.

(20I4). "Conferências Introdutórias à Psicanálise". In: Freud, Obras Completas, tradução S. Tellaroli, revisão Paulo César de Souza, São Paulo: Companhia das Letras, 20I4, v. I3.

(20I6). "Três ensaios sobre a teoria da sexualidade". In: Freud, Obras Completas, tradução Paulo César de Souza, São Paulo: Companhia das Letras, v. 6.

Нuot, H. (1991). Do sujeito à imagem: uma história do olho em Freud, tradução Cláudia Berliner, São Paulo: Escuta.

Ibertis, C. (2008). As tramas de Mnemosine: a memória nos primórdios da teoria freudiana, Tese de doutorado, Campinas: Ed. UNICAMP.

(20I5). "Tacto y reflexividad: una aproximación entre Condillac y Freud". In: CAORsi, C. e Navia, R. (compiladores), Actas del II Congreso de la Sociedad Filosófica del Uruguay, Montevideo, SFU, pp. 989-999.

(20I7). "Figuração e figurabilidade: no início eram as sensações". In: Revista Natureza Humana, São Paulo, v. 19, n. I, jan./jul., pp. 57-74.

Kastrup, V. (2013) “Será que cegos sonham? O caso das imagens táteis distais". In: Psicologia em Estudo, Maringá, v. I8, n. 3, pp. 43I-440, Jul./Set. 
Lecourt, E. (1997). Freud e o universo sonoro: o tique-taque do desejo, tradução Estela dos Santos Abreu, revisão Vera Ribeiro, Goiânia: Editora da UfG.

Winograd, M. e Costa Mendes, L. (2009). "Qual o corpo para psicanálise? Breve ensaio sobre o problema do corpo na obra de Freud". In: Psicologia: Teoria e Prática, v. II, n. 2, pp. 2II-223. 